\title{
Diagnostic accuracy of chromohysteroscopy in women with unexplained infertility
}

\author{
Kanika Chopra $^{1 *}$, S. S. Trivedi ${ }^{2}$, Sharda Patra ${ }^{1}$
}

\begin{abstract}
${ }^{1}$ Department of Obstetrics and Gynecology, Lady Hardinge Medical College, New Delhi, India
${ }^{2}$ Department of Obstetrics and Gynecology, S.G.T Medical College, Gurgaon, Haryana, India
\end{abstract}

Received: 19 April 2017

Accepted: 18 May 2017

\author{
*Correspondence: \\ Dr. Kanika Chopra, \\ E-mail: kank2kanu@yahoo.co.in
}

Copyright: (c) the author(s), publisher and licensee Medip Academy. This is an open-access article distributed under the terms of the Creative Commons Attribution Non-Commercial License, which permits unrestricted non-commercial use, distribution, and reproduction in any medium, provided the original work is properly cited.

\begin{abstract}
Background: Chronic endometritis has been related to infertility but it is usually asymptomatic and the diagnosis is rarely suspected clinically. In cases of absence of any macroscopic abnormalities during conventional hysteroscopy, endometrial dyeing using methylene blue help identify abnormal areas and coupled with the histopathological examination gives a better diagnosis of endometritis.

Methods: This study was conducted on 100 infertile women in Department of Obstetrics and Gynecology at Lady Hardinge Medical College, New Delhi over a period of one year. All women under- went hysteroscopy followed by chromohysteroscopy using $1 \%$ methylene blue dye. Biopsy was taken from light and dark stained areas. The histopathology results of these samples were compared and analyzed in relation with hysteroscopic and chromohysteroscopic findings and diagnostic accuracy calculated.

Results: Out of 100 women who underwent dianostic hysteroscopy 68 cases had normal findings and 32 had abnormal finding and on chromohysteroscopy light staining pattern was seen in 56 cases and 44 cases had dark staining. Histopathology of biopsy tissue from these dark stained areas showed endometritis in $50 \%$ (22 out of 44 cases) and normal endometrium in 50\% (22 out of 44) cases, and biopsy from light stained area showed chronic endometritis in 5.35\% (3 out of 56) cases and remaining $94.65 \%$ had normal endometrium. Diagnostic accuracy of chromohysteroscopy were sensitivity $=88 \%$, specificity $=70.66 \%, \mathrm{PPV}=50 \%, \mathrm{NPV}=94.6 \%$.

Conclusions: Chromohysteroscopy is a simple and effective technique for diagnosing endometrial pathology in cases of infertility.
\end{abstract}

Keywords: Chronic endometritis, Chromohysteroscopy, Infertility

\section{INTRODUCTION}

Infertility is defined as failure to conceive within one year of regular intercourse without the use of contraception, and is found in $10-15 \%$ of all couples. ${ }^{1}$ Among the uterine factors chronic endometritis contribute to around $0.8-19 \%$ cases. $^{2}$ Inspired from wide success of chromoendoscopy in the field of gastroenterology, the possibility to apply vital stains to the endometrium has come to the mind of gynaecologists. The endometrium does not absorb any dye in normal circumstances.

However, it does absorb in pathological states due to tissue changes. Recently, methylene blue dye has been used to stain endocervix and endometrium during hysteroscopy and distinctive staining patterns have been observed. ${ }^{3}$ 
This study was proposed to study the diagnostic accuracy of chromohysteroscopy for detection of subtle endometrial leasions in cases of unexplained infertility, which has not been used as a diagnostic modality so far in clinical practice. Hence, the current study was done to evaluate the role of chromohysteroscopy in detecting endometrial pathologies in patients of infertility using a safe, readily available and a cost-effective dye, methylene blue.

\section{METHODS}

This was a prospective observational study carried out in the Department of Obstetrics and Gynecology at Lady Hardinge Medical College, Delhi over a period of one year. Ethical clearance was taken from Institutional Ethical Committee. Hundred women with complaint of unexplained infertility were recruited after written informed consent. Detailed history and clinical examination were followed by baseline investigations. Patients were taken up for diagnostic hysteroscopy followed by chromohysteroscopy and guided biopsy was taken and sent for histopathology.

The cervical canal was visualized after which uterine cavity was observed, first in its totality and then systematically in each portion of the fundus, anterior wall, posterior wall, lateral walls and the uterine cornua and the findings were noted. Five millilitre of $1 \%$ methylene blue was introduced through the hysteroscopic inlet. After five minutes of waiting, distending medium flow was continued again and endometrium was washed. Uterine cavity was then visualized for the staining pattern and findings were recorded. Biopsies were obtained from dark and light stained areas and sent for histopathological examination in formalin. All the findings of hysteroscopy and chromohysteroscopy were compared with histopathological findings. Sensitivity, specificity, positive predictive and negative predictive values were calculated to assess diagnostic accuracy of hysteroscopy and chromohysteroscopy using histopathology as the gold standard.

\section{RESULTS}

In the present study, mean age of cases was $28.23 \pm 3.72$ years (Table 1).

Table 1: Distribution of cases according to age.

\begin{tabular}{|lll|}
\hline Age (yrs) & No. of cases $(\mathbf{N})$ & $\%$ \\
\hline $20-25$ & 27 & 27 \\
\hline $26-30$ & 55 & 55 \\
\hline $31-35$ & 15 & 15 \\
\hline 36 & 3 & 3 \\
\hline Total & 100 & 100 \\
\hline
\end{tabular}

Mean age: $28.23 \pm 3.722$

Seventy three cases had primary infertility and twenty seven had secondary infertility (Table 2). Of the 100 cases, 68 had normal hysteroscopic findings and 32 had abnormal findings.

Table 2: Distribution of cases according to type of infertility.

\begin{tabular}{|l|l|l|}
\hline Type of infertility & No. of cases (N) & $\%$ \\
\hline Primary & 73 & 73 \\
\hline Secondary & 27 & 27 \\
\hline Total & 100 & 100 \\
\hline
\end{tabular}

Table 3: Distribution of cases according to hysteroscopy findings.

\begin{tabular}{|llll|}
\hline $\begin{array}{l}\text { Overall } \\
\text { findings }\end{array}$ & & $\begin{array}{c}\text { No. of } \\
\text { cases (n) }\end{array}$ & $\begin{array}{l}\text { Percent } \\
\text { Normal }\end{array}$ \\
\hline Abnormal & & 68 & 68 \\
\hline & & 32 & 32 \\
\hline & $\begin{array}{l}\text { Intracavitary lesions } \\
\text { Subseptate/arcuate/ } \\
\text { Rudimentary horn }\end{array}$ & 18 & 56.25 \\
\hline & Submucous fibroids & 5 & 16.66 \\
\hline & Polyps & 5 & 27.77 \\
\hline & Micropolyps & 3 & 16.66 \\
\hline & Necrotic growth & 1 & 5.55 \\
\hline Bony spicule & $1 *$ & 5.55 \\
\hline & Endometrial lesions & 14 & 43.75 \\
\hline $\begin{array}{l}\text { Diffuse endometrial } \\
\text { disease }\end{array}$ & 11 & 78.57 \\
\hline $\begin{array}{l}\text { Shaggy } \\
\text { endometrium }\end{array}$ & 5 & 45.45 \\
\hline Flimsy adhesions & 4 & 36.36 \\
\hline $\begin{array}{l}\text { Dense adhesions/ } \\
\text { synechiae }\end{array}$ & 2 & 18.18 \\
\hline $\begin{array}{l}\text { Hyperemia with } \\
\text { white spots }\end{array}$ & 3 & 21.43 \\
\hline
\end{tabular}

*1 bony spicule and arcuate uterus had associated findings of hyperemia.

Amongst the cases that had abnormal hysteroscopic findings 18 had intracavitary lesions and 14 had endometrial lesions. In the cases who had intracavitary lesion $(n=18)$, subseptate uterus, arcuate uterus and rudimentary horn was seen in 1case each (confirmed on laproscopy). Submucous fibroids and polyps were there in 5 cases each. Presence of micropolyps was seen in 3 cases followed by necrotic growth and bony spicule in one each.

Amongst the women who had endometrial lesions $(n=14), 11$ had diffuse endometrial disease (shaggy endometrium in 5, flimsy adhesions in 4 and dense adhesions/ synechiae in 2 women) and the remaining 3 patients had diffuse hyperemia with white spots as can be appreciated in Table 3.

Biopsy findings in patients with normal and abnormal hysteroscopy showed endometritis in 13 out of 68 cases and 12 out of 32 cases respectively (Table 4 ). 
Table 4: Diagnostic accuracy of conventional hysteroscopy in detection of endometritis.

\begin{tabular}{|c|c|c|c|}
\hline \multirow[t]{2}{*}{ Hysteroscopy } & \multicolumn{2}{|c|}{ Histopathological findings } & $\begin{array}{l}\mathbf{p} \\
\text { value }\end{array}$ \\
\hline & $\begin{array}{l}\text { Endometritis } \\
\mathrm{N}(\%)\end{array}$ & $\begin{array}{l}\text { Normal } \\
\text { endometrium } \\
\mathrm{N}(\%)\end{array}$ & \multirow{3}{*}{0.48} \\
\hline $\begin{array}{l}\text { Abnormal } \\
(\mathrm{N}=32)\end{array}$ & $12(37.50)$ & $20(62.50)$ & \\
\hline $\begin{array}{l}\text { Normal } \\
(\mathrm{N}=68)\end{array}$ & $13(19.12)$ & $55(80.88)$ & \\
\hline
\end{tabular}

Diagnostic accuracy of hysteroscopy in detecting chronic endometritis was sensitivity $=48 \%$, specificity $=73.33 \%$,
$\mathrm{PPV}=37.50 \%, \mathrm{NPV}=80.88 \%,+\mathrm{LR}=1.77,-\mathrm{LR}=0.34$ and $\mathrm{AUC}=0.607$ (Table 7 and Figure 1).

Table 5: Distribution of cases according to chromohysteroscopy findings.

\begin{tabular}{|c|c|c|}
\hline $\begin{array}{l}\text { Chromohysteroscopic } \\
\text { findings }\end{array}$ & No. of cases $(\mathbf{N})$ & $\%$ \\
\hline Light stain & 56 & 56 \\
\hline Dark stain & 44 & 44 \\
\hline Total & 100 & 100 \\
\hline
\end{tabular}

In Table 5, it was observed that 56 out of 100 cases had light staining of endometrium in comparison to 44 cases which had dark stained endometrium.

Table 6: Diagnostic accuracy of chromohysteroscopy in detection of endometritis.

\begin{tabular}{|c|c|c|c|}
\hline Chromohysteroscopy & Histopathological f & & P value \\
\hline & Endometritis N (\%) & Normal endometrium N (\%) & \\
\hline Dark stain $(\mathrm{N}=44)$ & $22(50)$ & $22(50)$ & \\
\hline Light stain $(\mathrm{N}=56)$ & $3(5.35)$ & $53(94.65)$ & 0.000 \\
\hline
\end{tabular}

Table 7: Comparison of various statistical parameters of chromohysteroscopy and hysteroscopy.

\begin{tabular}{|lll|}
\hline $\begin{array}{l}\text { Statistical } \\
\text { parameters }\end{array}$ & Chromohysteroscopy & Hysteroscopy \\
\hline $\begin{array}{l}\text { Sensitivity } \\
\text { Specificity }\end{array}$ & $88 \%$ & $48 \%$ \\
\hline $\begin{array}{l}\text { Positive } \\
\text { predictive } \\
\text { value }\end{array}$ & $50.66 \%$ & $73.33 \%$ \\
\hline $\begin{array}{l}\text { Negative } \\
\text { predictive } \\
\text { value }\end{array}$ & $94.60 \%$ & $37.50 \%$ \\
\hline $\begin{array}{l}\text { Positive } \\
\text { likelihood } \\
\text { ratio }\end{array}$ & 2.99 & $80.88 \%$ \\
\hline $\begin{array}{l}\text { Negative } \\
\text { likelihood } \\
\text { ratio }\end{array}$ & 0.16 & 1.77 \\
\hline $\begin{array}{l}\text { Area under } \\
\text { ROC curve }\end{array}$ & 0.793 & 0.34 \\
\hline
\end{tabular}

Histopathology of biopsy tissue from these dark stained areas (Figure 2) showed endometritis in 50\% (22 out of 44 cases) and normal endometrium in $50 \%$ (22 out of 44 ) cases. Rest 56 cases had light staining pattern (Figure 3 ) on chromohysteroscopy. Their biopsy samples showed chronic endometritis in $5.35 \%$ (3 out of 56) cases and remaining $94.65 \%$ had normal endometrium on histopathology (Table 6). Based on this data diagnostic accuracy of chromohysteroscopy in detecting chronic endometritis was sensitivity $=88 \%$, specificity $=70.66 \%$,
$\mathrm{PPV}=50 \%, \quad \mathrm{NPV}=94.6 \%, \quad+\mathrm{LR}=2.99, \quad-\mathrm{LR}=0.16 \quad$ and AUC $=0.793$ (Table 7 and Figure 1).

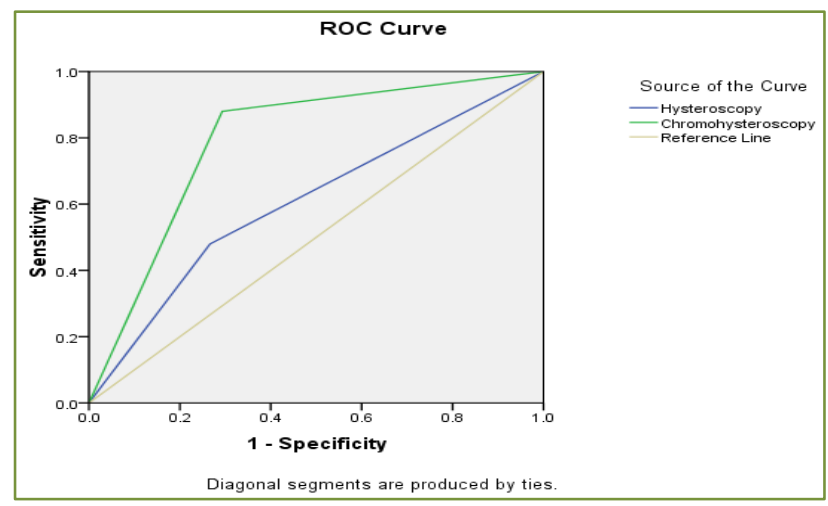

Figure 1: Comparison of ROC curves of hysteroscopy and chromohysteroscopy.

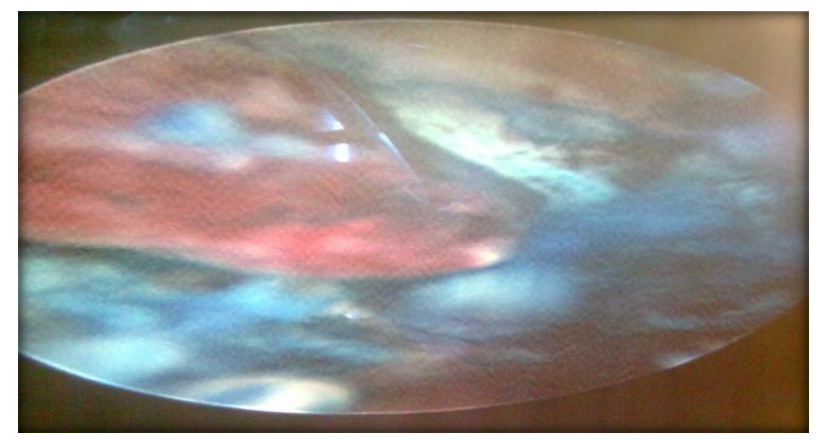

Figure 2: Dark staining of endometrium with unstained polyp on chromohysteroscopy. 


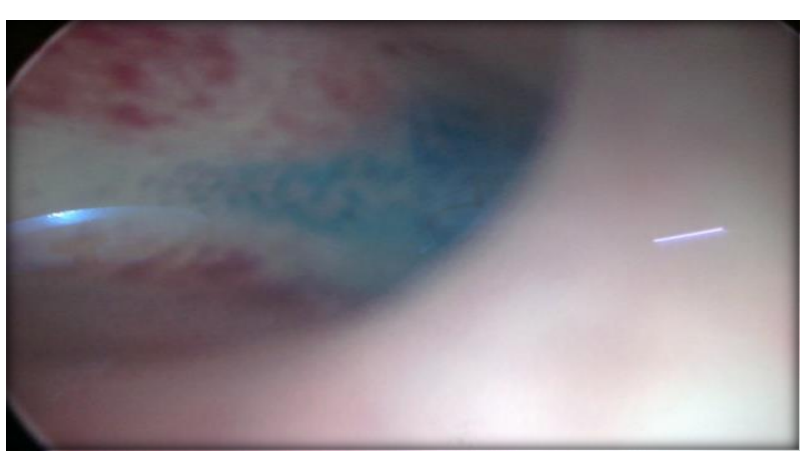

Figure 3: Light staining of endometrium on chromohysteroscopy.

\section{DISCUSSION}

Hysteroscopy enables the gynaecologists to detect intrauterine lesions but there are certain instances where the diagnostic accuracy of the gross observations is not sensitive or specific enough. This led to the birth of chromohysteroscopy technique with the belief that it would help in early and accurate detection of pathologies of the endometrium.

In the present study, mean age of cases was $28.23 \pm 3.72$ years. Maximum number of cases was in the range of 2630 years. This finding is in accordance with other studies on chromohysteroscopy (La sala GB, Safali et al and Deveci et al). ${ }^{4-6}$ In these studies, mean age also corresponds to 27-29 years.

Majority of cases were of primary infertility (73\%) and rest $27 \%$ had secondary infertility. The mean duration of infertility in cases was $6.97 \pm 3.80$ yrs with minimum duration of 1 year and maximum of 18 yrs. Present study is comparable to study of La Sala GB 1998 in which duration of infertility ranged from 2-10 years with a mean of 5.6 years. $^{4}$

The diagnostic accuracy of hysteroscopy for detection of endometrial lesions in present study was sensitivity $=48 \%$, specificity $=73.33 \%, \quad \mathrm{PPV}=37.50 \%, \quad \mathrm{NPV}=80.88 \%$. Micropolyps in our study was seen in 3 cases out of 100 and all had endometritis on histopathology. Cicinellie et al stated that micropolyps were always associated with stromal edema, endometrial thickening and focal or diffuse periglandularhyperemia. ${ }^{7}$ This study aimed to describe these lesions and evaluate their inflammatory significance by comparing hysteroscopic and histological findings. 820 women underwent hysteroscopy and endometrial biopsy. Sensitivity, specificity, positive and negative predictive values and accuracy of micropolyp's presence, for the diagnosis of chronic endometritis were calculated as $54 \%, 99 \%, 94 \%$ and $89 \%$ respectively. So, it was concluded that presence of endometrial micropolyps at fluid hysteroscopy is significantly associated with endometrial inflammation and can be considered as a reliable diagnostic sign for this pathology.
Diagnostic accuracy of chromohysteroscopy for detection of endometrial lesions in patients with unexplained infertility in our study was sensitivity $=88 \%$, specificity $=70.66 \%, \mathrm{PPV}=50 \%, \mathrm{NPV}=94.6 \%$. Similarly, Tansu $\mathrm{K}$ et al assessed the role of chromohysteroscopy in evaluation of endometrium in patients with at least two consecutive IVF failures (recurrent IVF failure cases) despite good quality embryo transfer. ${ }^{8}$ Sixty four patients in whom conventional hysteroscopy did not show any apparent endometrial pathology were included in the study and all underwent chromohysteroscopy. Diffuse light blue staining was considered normal. Focal dark blue staining above the internal cervical ostium regardless of size and number of stained areas were considered positive findings. The study group was grouped according to the staining characteristics. Group I included 22 patients in whom focal dark staining was observed. Group II included 41 patients in whom diffuse light blue staining without dark areas was observed. Histopathological examination revealed 9 cases of endometritis in group I (40.9\%). On the other hand, four cases of endometritis were diagnosed in group II $(9.7 \%)$. There was a statistically significant difference in the incidence of endometritis between two groups $(p=0.007)$. The power of dark staining for detection of endometritis was calculated as follow: sensitivity $69.2 \%$, specificity $74 \%$, positive predictive value $40.9 \%$ and negative predictive value $90.2 \%$. Thus, it was observed that on chromohysteroscopy, diffuse light blue staining without dark areas strongly suggested a normal endometrium free of endometritis and focal dark blue staining signified areas of endometritis. It was concluded in this study that chromohysteroscopy improved the efficacy of hysteroscopy in recurrent IVF failure and it was suggested that diffuse light blue staining without dark areas signified a normal endometrium free of endometritis. Thus, our figures are comparable to study on chromohysteroscopy in IVF failure by TansuKucuk et al. ${ }^{8}$

Chromohysteroscopy is thus, a novel technique that has not been pursued much, but appears to have potential in improving the efficacy of conventional hysteroscopy by detecting the missed endometrial pathologies. It was hypothesized that chromohysteroscopy would decrease the inter-observer variations during hysteroscopy and would increase its accuracy in detection of endometrial diseases.

To the best of our knowledge and extensive search of literature is the first study of application of chromohysteroscopy in infertility patients and we found that chromohysteroscopy increases the accuracy of conventional hysteroscopy in detecting endometrial pathologies and strongly excluding those free from endometrial disease. We also found that it is a useful adjunct that facilitated quick detection of endometrial lesions and minimized inter observer variation. Most of IVF-ET programs continue to perform HSG and hysteroscopy only for assessment of the uterine cavity in 
patients who underwent IVF-ET. Today, all investigations of and therapies for infertility are subject to scrupulous cost-benefit analysis. We believe that use of chromohysteroscopy as a routine investigation in women who will undergo IVF-ET would aid in patient selection, ultimately reducing the failures and therefore the costs of IVF-ET. So, the results can be tremendously improved with application of chromohysteroscopy along with these two techniques. We thus recommend regular application of chromohysteroscopy in diagnosing endometrial disease along with blind premenstrual EB and conventional hysteroscopy during work up of patients with infertility

\section{ACKNOWLEDGMENTS}

Author would like to thank Dr. S. S Trivedi for support, encouragement, guidance to finish this work. Author also sincerely thankful to Dr. Sharda Patra, Professor, Department of Obstetrics and Gynecology, Lady Hardinge Medical College, New Delhi for her amazingly brilliant suggestions and guidance throughout the study.

Funding: No funding sources

Conflict of interest: None declared

Ethical approval: The study was approved by the Institutional Ethics Committee

\section{REFERENCES}

1. Forti G, Krasusz C. Clinical review 100: evaluation and treatment of the infertile couple. J Clin Endocrinol Metab. 1998;83:4177-88.
2. Farooki MA. Epidemiology and pathology of chronic endometritis. Int Surg. 1967;48:566-73.

3. Marconi G, Vilela M, Quintana R, Diradourian M, Young E, Sueldo C. New observations on endometrial physiology after transcervical injection of methylene blue dye. Fertil Steril. 2004;82:1700-4.

4. La Sala GB, Montanari R, Dessanti L, Cigarini C, Sartori F. The role of diagnostic hysteroscopy and endometrial biopsy in assisted reproductive technologies. Fertil Steril. 1998; 70:378-80.

5. Küçük T, Safali M. Chromohysteroscopy for the evaluation of endometrium in recurrent in vitro fertilization failure. J Assist Reprod Genet. 2008;25:79-82.

6. Kucuk T, Deveci S. Can chromohysteroscopy help target endometrial biopsy in post menopausal bleeding. Europ J Gynecol Onco. 2008;29(2):165-7.

7. Cicinelli E, Resta L, Nicoletti R. Endometrial micropolyps at fluid hysteroscopy suggest the existence of chronic endometritis. Hum Reprod. 2005;20:1386-9.

8. Kucuk T, Deveci S. Chromohysteroscopy for evaluation of endometrium in recurrent miscarriage. Clin Exp Obstet Gynecol. 2008;35(2):133-6.

Cite this article as: Chopra K, Trivedi SS, Patra S. Diagnostic accuracy of chromohysteroscopy in women with unexplained infertility. Int J Reprod Contracept Obstet Gynecol 2017;6:2955-9. 